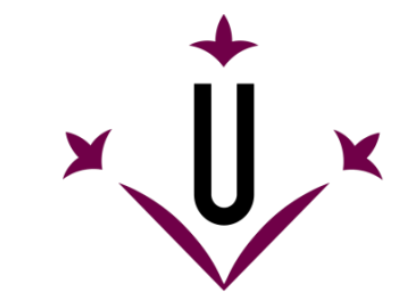

Universitat de Lleida

Document downloaded from:

http://hdl.handle.net/10459.1/69004

The final publication is available at:

https://doi.org/10.1016/i.ecolind.2010.03.018

Copyright

cc-by-nc-nd, (c) Elsevier, 2010 


\section{Aquatic Conservation:}

Marine and Freshwater Ecosystems

WILEY

\section{ASSESSING THE ECOLOGICAL STATUS IN SPECIES-POOR SYSTEMS: A FISH-BASED INDEX FOR MEDITERRANEAN RIVERS}

\begin{tabular}{|c|c|}
\hline Journal: & Aquatic Conservation: Marine and Freshwater Ecosystems \\
\hline Manuscript ID: & draft \\
\hline Wiley - Manuscript type: & Research Article \\
\hline $\begin{array}{r}\text { Date Submitted by the } \\
\text { Author: }\end{array}$ & $\mathrm{n} / \mathrm{a}$ \\
\hline Complete List of Authors: & $\begin{array}{l}\text { Hermoso, Virgilio; University of Huelva, Biología Ambiental y Salud } \\
\text { Pública } \\
\text { Clavero, Miguel; Centre Tecnològic Forestal de Catalunya, Grup } \\
\text { d Ecologia del Paisatge, Àrea de Biodiversitat; Universitat de } \\
\text { Girona, Departament de Ciències Ambientals } \\
\text { Blanco-Garrido, Francisco; University of Huelva, Biología Ambiental } \\
\text { y Salud Pública } \\
\text { Prenda, Jose; Universidad de Huelva, Biologia Ambiental }\end{array}$ \\
\hline Keywords: & $\begin{array}{l}\text { ANNA, bioassessment, community, freshwater fish, invasive } \\
\text { species, site-specific indices, type-specific indices, integrity }\end{array}$ \\
\hline
\end{tabular}

\section{S) ScholaroNE \\ Manuscript Central}




\section{ASSESSING THE ECOLOGICAL STATUS IN SPECIES-POOR SYSTEMS: A FISH- BASED INDEX FOR MEDITERRANEAN RIVERS.}

Virgilio Hermoso $^{1}$, Miguel Clavero ${ }^{2,3}$, Francisco Blanco-Garrido ${ }^{1}$ and José Prenda ${ }^{1}$.

${ }^{1}$ Departamento de Biología Ambiental y Salud Pública, Universidad de Huelva. Avda. Andalucía s/n, 21071 Huelva, Spain.

${ }^{2}$ Grup d'Ecologia del Paisatge, Àrea de Biodiversitat, Centre Tecnològic Forestal de Catalunya. Pujada del Seminari s/n, 25280 Solsona, Spain.

${ }^{3}$ Departament de Ciències Ambientals, Universitat de Girona. Campus de Montilivi, 17071 Girona, Spain.

Running Head: Assessment of Mediterranean river's health

Corresponding author:

Virgilio Hermoso

e-mail: virgilio.hermoso@gmail.com

Tlf: +34 959219895

Fax: +34 959219876 


\begin{abstract}
The assessment of the ecological status of freshwater ecosystems is a key issue for many international laws as the Water Framework Directive in light of the actual impoverished status of such ecosystems. Different multimetric approaches have been successfully developed all around the world in different freshwater environments. However multimetric indices are difficult to apply in Mediterranean rivers basins, where freshwater fish communities feature very low species richness per site and high number of endemics with generalist and opportunistic life strategies. A site-specific approach was followed to develop an adaptation of the multimetric concept in the Index of Community Integrity. The presence-absence of ten native freshwater fish species was modeled and used to assess the deviation of the observed and expected community composition at reference condition. These deviations were transformed into probabilities to belong to a reference site and species by species measures were then integrated in a final score. The use of presence-absence only data reduces the possible errors associated to incorrect estimations of species' abundance and its seasonal changes. The index was sensitive to both habitat and biotic disturbances while irresponsible to natural sources of variation. To our concern, this is the first index specifically tested to be responsible to biotic perturbations, which traditionally have been forgotten pressures in Indices of Biotic Integrity.
\end{abstract}

KEYWORDS: ANNA, bioassessment, community, freshwater fish, invasive species, sitespecific indices, type-specific indices, integrity. 


\section{INTRODUCTION}

Assessing the ecological status of freshwater ecosystems has been a key issue in freshwater management for the last decades as a consequence of their poor conservation status. The importance of these ecosystems to human culture, welfare and development has lead them to a poor status (Malmqvist \& Rundle, 2002). Five main sources of perturbations are responsible for this situation: i) species introductions and translocation, ii) impoundment of rivers and water abstraction, iii) water quality deterioration (pollution or eutrophication), iv) habitat degradation and fragmentation and v) overexploitation (Allan \& Flecker, 1993; Collares-Pereira \& Cowx, 2004; Prenda et al., 2006). As a consequence, many freshwater fish species have become extinct or are highly endangered. This situation is particularly worrying in rivers of arid and semi-arid regions (Collares-Pereira \& Cowx, 2004). To face this serious situation many international laws as the Clean Water Act in the US or the European Water Framework Directive (WFD, E.C., 2000) try to address the problem requiring the protection and restoration of biological integrity as part of water quality standards.

According to the WFD the present status of all European rivers must be assessed and classified to five predefined levels of ecological integrity based on four biotic elements including freshwater fish. This bioassessment should help to evaluate the potential problems affecting rivers and to lead them to a good ecological status before 2015 by imposing effective corrective plans.

Many efforts have been devoted to the development of efficient tools to measure the ecological status of these systems based on freshwater fish. Karr (1981) originally designed an Index of Biotic Integrity (IBI) for north-eastern American rivers that followed a multimetric approach. The index was originally composed by twelve metrics reflecting important components of community ecology: taxonomic richness, habitat and trophic guild composition, individual health and abundance which were summed up in a final score. Following this multimetric approach many other indices have been developed throughout the world and adapted to specific conditions and requirements (Roset et al., 2007). Two different trends can be distinguish within recent European efforts: spatially-based or type-specific methods (Melcher et al., 2007;

Schmutz et al., 2007) and site-specific methods (Oberdorff et al., 2002; Pont et al., 2007) both based on the original Karr's multimetric index and the reference condition approach (Hughes et al., 1986; Reynoldson, 1997, Bailey et al., 1998). These methods compare an ecosystem potentially exposed to a stress against a similar ecosystem free from any perturbation or in the best possible condition (its maximum ecological potential or reference conditions), but differ in the way they find the reference conditions for a given site. The type-specific approach relies on grouping techniques to cluster reference sites in a set of homogeneous landscape or biological groups. Then a given site only has to be compared against the reference conditions of the group 
in which it is included, which are normally referred as the characteristics of the best preserved sites within each group. The site-specific approach does not require any classification and it simply finds specific reference conditions for every new given site according to its environmental characteristics. A site-specific index was the option selected for the development of the European Fish Index (EFI) which arose from the European FAME project (FAME, 2004) and is being applied to most of European rivers.

Type-specific predictive methods have been developed for other taxonomic groups, such as RIVPACS (Clarke et al., 2003) or AUSRIVAS (Simpson and Norris, 2000) on benthic macroinvertebrate communities. Instead of relying on elaborated metrics as the multimetric approaches do, these methods directly compare the observed and expected communities using presence-absence only data. However they have received little attention in freshwater fish indices (Hawkins, 2006; Kennard et al., 2006a; Carlisle et al., 2008).

Despite the EFI was not validated for Mediterranean rivers (Pont et al., 2007) and no similar index is available for this area, scarce efforts have been focused on the adaptation of an IBI to this area (Ferreira et al., 1996; De Sostoa et al., 2004; Ferreira et al., 2007). Mediterranean fish communities share common problems with other warm-water streams which make difficult to establish IBIs as a reduced number of species per site, a high number of endemisms per basin and high spatial and temporal changes in fish communities (Moyle and Randall, 1998; Moyle and Marchetti, 1999). Moreover, Mediterranean freshwater fish species have evolved in harsh environments (e.g. facing severe droughts and floods) and have generally developed short lifespans, generalist habitat use, opportunistic feeding strategies, high fecundity and early sexual maturity (e. g. Velasco et al., 1990; Vila-Gispert and Moreno-Amich, 2002). All these drawbacks may impose serious limitations to the development of an effective index in Mediterranean rivers, at least in its traditional approach, as in other similar environments even with richer freshwater fish communities (Shields et al., 1995; Harris and Silveira, 1999). All the previous attempts to the development of a bioassessment tool in the Mediterranean region followed a type-specific approach (e. g. Ferreira et al., 2007) while a site-specific has never been tried in this complex environment.

For all these reasons, in this study we develop a new approach to the assessment of the ecological status in Mediterranean rivers. A mix of site-specific and multimetric approaches was made to overcome the drawbacks commonly associated to them in scientific literature. Special care was put in the evaluation of the sensitivity of the index to biotic disturbances since, though they suppose a major recognized threat to the conservation of native communities it has traditionally received little attention.

\section{METHODS}


Study area

The Guadiana River basin is located in the South-Western Iberian Peninsula draining a total area of $67039 \mathrm{Km}^{2}$ to the Atlantic Ocean (Fig. 1). It features a typical Mediterranean climate, with high intra and interannual discharge variation, with severe floods and droughts. Mean air temperature ranges from 13 to $18.1{ }^{\circ} \mathrm{C}$, with a strong intra-annual variation in extreme temperatures. Mean annual precipitation ranges from 350 to $1200 \mathrm{~mm}$ (with a mean of 450 $\mathrm{mm})$.

Although it is a sparsely populated area $\left(28 \mathrm{hab} / \mathrm{Km}^{2}\right)$, landscape has been deeply transformed during the last century by agricultural activities. Almost a half of the basin $(49.1 \%)$ is currently being used for agriculture (30.6\% occupied with intensive agriculture as irrigated lands and $18.5 \%$ occupied with extensive agriculture, like olive groves or fruit trees). As a consequence, about $13000 \mathrm{Hm}^{3}$ of water is retained in 88 big reservoirs $\left(>1 \mathrm{Hm}^{3}\right)$ and more than 200 small ones $\left(<1 \mathrm{Hm}^{3}\right)$ for water supply. Other common human perturbations are related to river channel modifications due to river channelization and degradation and even completely depletion of the riparian forest.

Fish community and habitat characterization

Fish community was characterized in 241 localities through the basin, using electrofishing (Fig. 1). Sampling was conducted once at each location without block-nets along $100 \mathrm{~m}$ long stretches. This sampling effort has been proved to be sufficient to capture most species present, except for non-wadable rivers, as Filipe et al. (2004) suggest. This was not a major problem since no more than $2 \%$ of sites were non-wadable. Alternative methodological approaches similar to that used in other European countries for this kind of environments (Kestemont and Goffaux, 2002) were followed. All fish were released after we identified the individuals to species level.

Habitat was characterised through 38 environmental variables, covering three different spatial scales: site, reach and basin. These measures could be split in two categories: a) predictors that described the natural habitat variability in the basin and b) descriptors of human perturbation (Table 1). Two approaches were used in this characterization: in situ or remote measures, which described micro and mesohabitat characteristics in each locality, and GIS measures used to record variables from digital maps (Table 1). All the variables were checked for normality and transformed when necessary prior to analysis.

The original data was divided in two independent sub-sets: a reference data set used for building and calibrating the predictive model and a test data set used in conjunction with the reference to establish quality classes. Reference sites were characterised by low urban or agricultural land uses within the whole basin and at the reach scale (500 $\mathrm{m}$ around the sampling point).

Furthermore, bank and channel structure as well as the riparian zone should be in natural 
condition (Pont et al., 2007). To ensure that reference sites were not impacted by invasive fish, all sites where exotic species accounted for more of $5 \%$ of total fish abundance were also discarded (Kennard et al., 2006b).

Development of the Index of Community Integrity.

The Index of Community Integrity measures the general deviation of the observed community composition from an expected community in total absence of any source of perturbation (human or biotic) following the reference condition approach (Hughes et al., 1986; Reynoldson et al., 1997; Bailey et al., 1998). The index summarizes the partial evaluations made species by species for each site to be a reference site.

We first built and validated a predictive model describing the presence-absence of 10 native species in relation to environmental variables not affected by human perturbations (Table 1) only in reference sites. These set of non perturbed environmental variables were used to match test sites with the most similar environmental reference sites allowing site-specific predictions of expected taxonomic composition. An ANNA model (Linke et al., 2005) was used for this purpose which showed the best performance in our data in previous studies (data not shown). ANNA is a whole community predictive model (like RIVPACS) allowing the prediction of rare species which should be discarded in other traditional predictive methods like logistic regression. Logistic regression needs the number of presences-absences to be balanced and the number of predictors that can be used is highly limited by the number of available cases (e.g. Filipe et al., 2004). That makes the development of predictive models for species with very low prevalence impossible. In ANNA even rare species can be modelled following a continuous approach as a solution to the drawbacks of artificial grouping strategies (see Linke et al., 2005 for more details on ANNA models).

The ANNA model was built on a set of 70 reference sites and validated in an independent data set of 20 reference sites (calibration data set). Since the original number of reference sites found in the study area ( $\mathrm{n}=55$ sites) was not sufficient for both model construction and validation, some reference sites were also chosen from adjacent basins in the same biogeographical region (Tinto, Odiel and Guadalquivir basins). Although all these basins share most of their native species we introduced the variable basin as an additional predictor. Model performance was assessed through different tests carried out in the calibration data set. First, the slope and intercept of the $\mathrm{O} / \mathrm{E}$ line was not different from 1 and 0 respectively ( $b=1.063$, t-test, $\mathrm{p}=0.58$ and intercept $=0.058, \mathrm{p}=0.95$ ). Second, the prediction success measured as the area under the curve $(\mathrm{AUC}=0.79)$ of the Reciever Operating Characteristic (ROC) (Fielding and Bell, 1997) and the Standard Deviation of the $\mathrm{O} / \mathrm{E}$ values $\left(\mathrm{SD}_{\mathrm{O} / \mathrm{E}}=0.39\right)$, which improved that displayed by the null model ( $\left.\mathrm{SD}_{\text {null }}=0.45\right)$ and set close to the best possible model $\left(\mathrm{SD}_{\mathrm{R}}=0.38\right)$ according to Van Sickle et al. (2005). These two analyses showed the model to be valid and accurate enough to be 
used in the index minimizing the probability of committing type I and II statistical errors according to Linke et al. (2005). Once the model was validated, independent sub-models were built to predict the expected fauna in the reference localities used in the model construction to allow their inclusion in the index. To avoid pseudo-replication errors in these predictions each reference site used for building the model was run through it, without itself.

The basic unit used to construct the index was the probability of a given site to be a reference site, which depends on the deviation of the observed and the expected community composition from a reference site with similar environmental characteristics. The deviation of the observed presences-absences against the expected probabilities in absence of perturbations (O-E) was measured for each species in each site (referred as residuals hereafter). Note that since the index compares the community composition species by species we had ten different residuals for a given site. Negative values indicate species loss (the species was predicted to be present with a certain probability but it was absent). The lower the residuals, the higher the probability of presence unconfirmed hence. In the opposite extreme, positive residuals owe to observed presences with low predicted probabilities. These residuals were standardized to a $(0,1)$ normal distribution (x-mean/SD in the reference data set) and then transformed into probabilities to belong to a reference site (Fig 1). Since we assumed that residuals decreased with disturbance, we used only one-tailed evaluations for probabilities' calculations. With this approach we assumed all the 10 native species to be sensitive to any source of perturbation according to previous studies on species tolerances (data not shown). The probability of a site to be a reference site having a standardized residual $\mathrm{x}$ is obtained from the cumulative normal distribution function corresponding to that $\mathrm{x}$ value [pnorm(x), according to Pont et al. (2007)]. Each species measure was then summed up in the final index score. It ranged between 0 (the site has a null probability to be a reference site according to all the partial species' evaluations) and 10 (the site has a high probability to be a reference site according to all the partial species' evaluations) (Fig 2).

Scoring and validating the Index

To validate the index and to establish the cut-off points between quality classes we checked its relationships with impairment gradients and its response vs. other accepted indices.

A Principal Component Analysis (PCA) was carried out on the environmental matrix (Table 1) to identify a set of independent gradients representative of the main sources of environmental variation in the study area. The first three Principal Components (PC) accounted for the $37 \%$ of the original variance recording a longitudinal headwater-mouth gradient (PC1), a habitat impairment gradient (PC2) and a biotic perturbation gradient (PC3) (Table 2). As a first approach, the effects of these gradients on the index scores were explored through a General Linear Model (GLM), where each gradient was used as independent variables and the index 
score as dependent. The limits between quality classes were established to maximize the difference among the perturbation gradients while not responding to the longitudinal gradient (to avoid the effects natural variability) and reducing the risk of committing Type I (inferring impairment when it does not exist) and Type II (not detecting impairment when it does exist) errors. Statistical differences among quality classes along the gradients were tested through ANOVA analysis. Once established, quality classes were tested for concordance with other widely used indices measuring human disturbances in freshwater ecosystems. The Iberian Biomonitoring Working Party (IBMWP, Alba-Tercedor et al., 2002) is an index specially designed to measure water quality based on benthic macroinvertebrate communities. The QBR index (Munné et al., 2003) is used to evaluate the quality of riparian forest and riparian-zone habitats. Final scores of both indices were used in this analysis instead of their respective quality classes since we mainly aimed to explore concordant responses of the present classes in other indices' scores despite an intercalibration. An ANOVA analysis was used for this purpose. Although intercalibration exercises between the quality classes for different indices (ensuring concordance in the assignation of quality classes within different indices) are highly recommended (Sandin and Hering, 2004; Birk and Hering, 2006) this it is not the aim of this study. Significant differences in the scores of both indices among the Community Integrity Index quality classes would be expected if a good concordance between them existed and similar information was offered.

\section{RESULTS}

The Index of Comunity Integrity ranged between 1.7 and 8.3 and clearly discriminated between reference and test sites ( $\mathrm{t}$-test, $\mathrm{t}=5.5 \mathrm{p}<0.001$ ). The GLM analysis showed that both perturbation gradients (habitat and biotic) had significant effects on the scores of the index, but no effect was found for the natural longitudinal gradient (Table 3). The cut-off points fulfilled the goals we demanded. The limits for the bad-poor and high-good quality classes (Table 4) reduced the probability of Type I and II errors minimizing the probability of labelling a reference site as in bad condition and perturbed sites as in high condition. Different percentiles were used in both extremes to maximize the discriminatory power. The mean index's scores in the reference data set was used as limit between moderate-good quality classes, ensuring that only sites with a score higher than an average reference site could be labelled as in good condition, while in moderate condition otherwise. Similarly the limit between poor-moderate was set at the mean value of the perturbed sites. In this way only sites in a condition higher than an average perturbed site could be labelled as in moderate condition while in poor condition otherwise (Table 4). There were no significant differences in the longitudinal gradient among quality classes (ANOVA, $\mathrm{F}=0.5, \mathrm{p}=0.7$ ), while these were marginal in the habitat impairment gradient 
$(\mathrm{F}=1.8, \mathrm{p}=0.1)$ (Fig. 3). Although this marginal statistical significance, mean habitat impairment values followed a reasonable increasing tendency along the quality classes (Fig. 3). The values of the biotic perturbation gradient were clearly different among quality classes ( $\mathrm{F}=22.5$, $\mathrm{p}<0.001$ ) (Fig. 2).

The Index of Community Integrity showed a high concordance with the other two tested indices (Fig. 2). A previous analysis proved no redundancy between both indices and the pressure gradients used to calibrate the present index (Pearson's $r<|0.5|$ for all the relationships between the gradients in Table 2 and the QBR and IBMWP), avoiding circularity effects in the validation. There were significant differences in the scores of both alternative indices among present quality classes (ANOVA, $\mathrm{F}=13.5, \mathrm{p}<0.001$ for IBMWP and $\mathrm{F}=4.6, \mathrm{p}<0.001$ for $\mathrm{QBR}$ ). This result not only validates the present index but also supports and enhances the slight response it displayed when assessing the habitat quality impairment. Both QBR and IBMWP are especially dedicated to the assessment of riparian forest-environment quality (physic habitat) and water quality respectively. Given the high concordance they displayed we can ensure that these two sources of habitat degradation can be correctly assessed through the Index of Community Integrity, while co-variation issues between land uses and water quality could be masking the response of the index to both sources of perturbation in the habitat impairment gradient.

\section{DISCUSSION}

The Index of Community Integrity follows a site-specific comparison of community composition based on the reference condition approach. The presence-absence of ten native species was successfully modeled and used to evaluate the deviation between the observed and expected community composition. Species by species probability measures of each site to be a reference site were summed up in the final score of the index.

The reference condition approach (Hughes et al., 1986; Reynoldson et al., 1997, Bailey et al., 1998) in bioassessment defines biological integrity in terms of compositional similarity between present and expected optimal situations so it is assumed that human and biotic impairment affects the local community composition. Multimetric indices quantify the biological integrity through several community attributes (as changes in guilds-based metrics) rather than compositional comparisons. Since taxa are the basic unit of communities and hence aggregated biological organizations, alterations in taxonomic composition may occur before changes at other structural levels (Norris and Hawkins, 2000; Hawkins et al., 2000). Moreover, different members of the same ecological aggregation may not respond in the same way to a given disturbance showing independent responses to different types and degree of degradations (Thiollay, 1992; Lindermayer et al., 1999; Lindermayer et al., 2000). This could make indices 
insensitive to specific disturbances. Additional problems have been linked to multimetric approaches, such as circularity in the selection of sensitive metrics to conform the final index or the tendency to make Type I errors associated also to metrics selection (Norris and Hawkins, 2000). In addition, the development of complex indices with numerous metrics in rivers with a small number of native species, such as the Mediterranean rivers is difficult (Miller et al., 1988) and a good knowledge on species basic ecology aspects is needed for developing multimetric indices (Norris and Hawkins, 2000). However, this information is lacked at the moment and most of the ecological classifications are based on expert judgment. As an example a half of the species included in the European FAME project could not be correctly classified into different guilds because missing information, according to Schmutz et al. (2007a). A predictive approach which considers species composition instead of elaborated metrics seems a more efficient way to face the assessment of the ecological status hence.

However some predictive approaches based on species composition as RIVPACS or AUSRIVAS (Simpson and Norris, 2000; Clarke et al., 2003) simplify the complex effects of natural or perturbation induced changes on community composition through the use the $\mathrm{O} / \mathrm{E}$ species richness ratio as a synthetic measure of community integrity. Some important changes in ecosystem structure or function may not be detected through this simplistic approach (Karr and Chu, 2000; Norris and Hawkins, 2000). To overcome this drawback, changes at the whole community were considered in this study through species by species comparisons making the index more powerful and flexible according to Pont et al. (2006). Thus solutions to potential problems in both multimetric and richness-based approaches have been faced and overcome in this index.

Presence absence data has been used as the basis for the comparison between the observed and the expected communities. It could be expected these method to be insensitive to many stressors, because individual populations of some species can suffer a considerable degradation before going locally extinct. However, at the assemblage level, presence-absence data appears to be sufficiently robust to allow the detection of reasonably subtle differences among sites (Hawkins et al., 2000) and has widely been used in other common indices, such as RIPVPACS (Clarke et al., 2003). Population densities are submitted to greater temporal (seasonal and interannual) and spatial rates of change than presence-absence data even under natural conditions in Mediterranean and other similar harsh environments (Meffe and Minckley, 1987; Matthews and Marsh-Matthews, 2003; Magalhães et al., 2007). Species presences have been proved to be more persistent than abundance through natural dramatic climatic events (frequent in this kind of environments) as severe droughts or floods (Magalhães et al., 2007). This temporal variability usually forces researchers to validate their indices through time series to account for the effect of these natural changes (Pont et al., 2006; Collier, 2008). Although a temporal validation of the index would be desirable, it seems of less concern in a presence-absence index 
than when using highly seasonal dependent metrics. Furthermore, the characterization of species' abundances is largely more complex and difficult to standardize than the description of species' presences-absences. Key issues in sampling methodologies like sampling effort or methods have immediate consequences on bioassessment results (Lenat, 1993; Reynolds et al., 2003), so the simplest the information needed the more confident the results. This also has economic implications for the implementation of bioassessment programs, since the more information needed the higher the cost of recording it while a cost-efficient method is always desired (Schmutz et al., 2007a). Thus the use of presence-absence data supposes not only a considerable simplification for the implementation of the index but also a way to overcome other weakness related to the use of abundance data.

The summing of metrics or measures to produce a final index score cannot be recommended unless it could be demonstrated every single partial measure to vary in the same direction and with the same magnitude of response to damage (Norris and Hawkins, 2000). The present index fulfils this exigency since the residuals between the observed presences-absence and the expected probabilities tend to decrease with human-biotic impairment. Sensitive species will disappear at perturbed sites deriving high negative residuals in case of being predicted to be present while tolerant species will remain at perturbed sites implying higher positive residuals. Then all this partial evaluations are transformed into probabilities of a site to be a reference site all ranging between 0-1. Every species' evaluations had the same weight within the final index score since all their derived probabilities for the site to be a reference site were summed up without any weighting given that every species was proved to be sensitive to any source of perturbation in a previous study (data not shown). Even rare species with very low prevalence were successfully modelled through the ANNA model and included in the index overcoming the potential weakness of this no-multimetric predictive approach according to Pont et al. (2007). They justify the use of elaborated metrics instead of real data due to the unfeasibility to model rare species. The use of all the species with no weights and the wide range of environmental conditions accounted for through data from the whole basin ensured the index to respond to a broad range of perturbations.

The Index of Community Integrity showed to be sensitive to both human and biotic while not at all to the natural spatial variation. The ability to distinguish between natural and impairmentinduced changes in community composition is a crucial point in bioassessment (Fausch et al., 1990; Huges et al., 1998; Norris and Hawkins, 2000). The lack of concordance of the present index and the longitudinal gradient was managed through the predictive model which accounted for a substantial portion of the spatial variability of species' presence-absence making its scores independent of natural variations. A site-specific approach was used in this study following the river continuum concept (Vanote et al., 1980) avoiding artificial classifications and their derived consequences on bioassessment. The effect of inaccurate a prioi top-down landscape 
classification and even a posteriori bottom-up biological classifications used in type-specific approaches (Schmutz et al., 2007b; Melcher et al., 2007) on predictive model performance and bioassessment results are being pointed out in Hermoso et al. (submitted). On the other hand good responses were found for all the sources of perturbation tested. A strong response was found for different sources of habitat perturbation given the concordance of this index with other two commonly used indices to assess water quality and the status of the riparian forest and the naturalness of the riparian zone. Is also remarkable the response showed to the biotic disturbance measured as the relative dominance of exotic species within the whole fish community. Attending to relative measures the effect of local species richness and abundance were discarded. Exotics are considered one of the major threats to the conservation of native fish communities and to the ecological status of rivers hence (Kaufman, 1992; Godinho and Ferreira, 2000; Clavero et al., 2004). However it has not been extensively considered in recent works (Oberdorff et al., 2002; Pont et al., 2007; Ferreira et al., 2007) while was emphasized as a main issue to consider when assessing the ecological status (Pont et al., 2006). Moreover impacts of exotic species on the ecological status are difficult to prove and assess through physic-chemical habitat quality measures since exotics neither alter any other ecosystem attribute besides from biotic communities nor may be related to other human impacts (a site in very good physic-chemical condition may be completely dominated by exotics) though it is difficult to distinguish between both sources of perturbation (Light and Marchetti, 2007). That makes especially important for any index to be sensitive to biotic disturbances. Thus the present index is capable to detect not only commonly measured habitat perturbations but also and more important the degradation status of the native freshwater fish community. Furthermore the relative weight of different factors can be assessed in a post-hoc diagnostic using each species partial evaluations which may help to the development of efficient corrective plans to lead the assessed freshwater ecosystems to a good ecological status as the WFD requires.

The use of the present index in a broader area would not be a complicated task since the only requisite needed is the development of accurate predictive models for local faunas. In this way the Index of Community Integrity could be adapted and validated in other Mediterranean basins which at the moment lack of efficient fish-based bioassessment tools. Through a site-specific approach the limitations imposed by river types (the index is only applicable to a river previously included within the same type) are overcome. Given the special characteristics of the Mediterranean freshwater fish communities (high basin endemicity) a basin approach seems to be the best option for site specific predictive methods. A multi-species predictive approach is highly recommended for other Mediterranean basins given the reduced distribution areas of some endemics. Finally a deeper characterization of the different sources of perturbation would allow to better study the index response and potential. 


\section{ACKNOWLEDGEMENT}

The fieldwork was financed by the Confederación Hidrográfica del Guadiana through the project "Diseño y Explotación de la Red de Control Biológico de la Cuenca del Río Guadiana" and the Ministry of Science and Technology (REN2002-03513, CGL2005-02699). V. Hermoso holds a pre-doctoral fellowship financed by the Spanish Ministry of Education (AP-2004-1414).

\section{REFERENCES}

Alba-Tercedor, J., Jáimez-Cuéllar, P., Álvarez, M., Avilés, J., Bonada, N., Casas, J., Mellado, A., Ortega, M., Isabel Pardo, Prat, N., Rieradevall, M., Robles, S., Sáinz-Cantero, C. E., Sánchez-Ortega, A., Suárez, M. L., Toro, M., Vidal-Abarca, M. R., Vivas, S. , ZamoraMuñoz, C. 2002. Caracterización del estado ecológico de ríos mediterráneos ibéricos mediante el índice IBMWP (antes BMWP'). Limnetica 21: 175-185.

Allan, J. D., Flecker, A. S. 1993. Biodiversity conservation in running waters. Identifying the major factors that threaten destruction of riverine species and ecosystems. BioScience 43: 32-43.

Bailey, R. C., Kennedy, M. G., Dervish, M. Z., Taylor, R. M. 1998. Biological assessment of freshwater ecosystems using a reference approach: comparing predicted and actual benthic invertebrate communities in Yukon streams. Freshwater Biology 39: 765-774.

Birk, S., Hering, D. 2006. Direct comparison of assessment methods using benthic macroinvertebrates: a contribution to the EU Water Framework Directive intercalibration exercise. Hydrobilogia 56: 401-415.

Carlisle, D. M., Hawkins, C. P., Meador, M. R., Potapova, M., Falcone, J. 2008. Biological assessment of Appalachian streams based on predictive models for fish, macroinvertebrate, and diatom assemblages. Journal of the North American Benthologica Society 27: 16-37.

Clarke, R. T., Wright, J. F., Furse, M. T. 2003. RIVPACS models for predicting the expected macroinvertebrate fauna and assessing the ecological quality of rivers. Ecological Modelling 160: 219-233.

Clavero, M., Blanco-Garrido, F., Prenda, J. 2004. Fish fauna in Iberian Mediterranean basins: biodiversity, introduced species and damming impacts. Aquatic Conservation: Marine and Freshwater Ecosystems 14: 575-585.

Collares-Pereira, M. J., Cowx, I. G. 2004. The role of catchment scale environmental management in freshwater fish conservation. Fisheries Management and Ecology 11: 303312.

Collier, K. J. 2008. Temporal patterns in the stability, persistence and condition of stream macroinvertebrate communities: relationship with catchment land-uses and regional climate. Freshwater Biology 53: 603-616.

E.C. (2000) Directive 2000/60/EC of the European Council and of the Council of 23 October 2000 establishing a framework for Community action in the field of water policy. Official Journal of the European Communities, L327 1-72.

FAME Consortium. 2004. Development, Evaluation and Implementation of a standardized Fishbased Assessment Method for the Ecological Status of European Rivers (FAME). Available at: http://fame.boku.ac.at

Fausch, K. D., Lyons, J., Karr, J. R., Angermeier, P. L. 1990. Fish communities as indicator of environmental degradation. American Fisheries Society Symposium 8: 123-144.

Ferreira, M. T., Caiola, N., Casals, F., Oliveira, J. M., De Sostoa, A. 2007. Assessing perturbation of river fish communities in the Iberian Ecoregion. Fisheries Management and Ecology 14: 519-530.

Fielding, A.H., Bell, J. F. 1997. A review of methods for the assessment of prediction errors in conservation presence/absence models. Environmental Conservation 24: 38-49. 
Filipe, A. F., Marques, T. A., Seabra, S., Tiago, P., Ribeiro, F., Moreira Da Costa, L., Cowx, I. G., Collares-Pereira, M. J. 2004. Selection of priority areas for fish conservation in Guadiana River Basin, Iberian Peninsula. Conservation Biology 18: 189-200.

Godinho, F.N., Ferreira, M.T. 2000. Composition of endemic fish assemblages in relation to exotic species and river regulation in a temperate stream. Biological Invasions 2: 231-244.

Harris, J. H, Silveira, R. 1999. Large-scale assessments of river health using an Index of Biotic Integrity with low-diversity fish communities. Freshwater Biology 41: 235-252.

Hawkins, C. P. 2006. Quantifying biological integrity by taxonomic completeness: its utility in regional and global assessment. Ecological Applications 16: 1277-1294.

Hawkins, C. P., Norris, R. H., Hogue, J. N., Feminella, J. W. 2000. Development and use of predictive models for assessing the biological integrity of streams. Ecological Applications 10: $1456-1477$.

Hermoso, V., Linke, S., Prenda, J. (submitted). Are large-scale landscape classifications derived from the WFD adequate to evaluate the ecological status of Iberian rivers?

Huges, R. M., Kaufmann, P. R., Herlihy, A. T., Kincais, T. M., Reynolds, L., Larsen, D. P. 1998. A process for developing and evaluating indices of fish assemblage integrity. Canadian Journal of Fisheries and Aquatic Sciences 55: 1618-1631.

Huges, R. M., Larsen, D. P., Omernik, J. M. 1986. Regional reference sites: a method for assessing stream potential. Environmental Management 10: 629-635.

Karr, J. R. 1981. Assessment of biotic integrity using fish communities. Fisheries 6: 21-27.

Karr, J. R., Chu, E. W. 2000. Sustaining living rivers. Hydrobiologia 422/423: 1-14.

Kaufman, L. 1992. Catastrophic changes in species rich freshwater ecosystems: The lessons of Lake Victoria. BioScience 42: 846-858.

Kennard, M. J., Harch, B. D., Pusey, B. J., Arthington, A. H. 2006b. Accurately defining the reference condition for summary biotic metrics: a comparison of four approaches. Hydrobiologia 572: 151-170.

Kennard, M. J., Pusey, B. J., Arthington, A. H., Harch, B. D., Mackay, S. J. $2006 a$. Development and application of a predictive model of freshwater fish assemblage composition to evaluate river health in eastern Australia. Hydrobiologia 572: 33-57.

Kestemont, P., Goffaux, D. 2002. Metric selection and sampling procedures for FAME. In Development, Evaluation \& Implementation of a Standardised Fish-Based Assessment Method for the Ecological Status of European Rivers- A Contribution to the Water Framework Directive (FAME). 88 pp. Available at: http://fame.boku.ac.at

Lenat, D. R. 1993. A biotic index for the southeastern United States: derivation and list of tolerance values, with criteria for assigning water-quality ratings. Journal of the North American Benthological Society 12: 279-290.

Light, T, Marchetti, M. P. 2007. Distinguishing between invasions and habitat changes as drivers of diversity loss among California's freshwater fishes. Conservation Biology 21: 434-446.

Lindermayer, B. D., Cunningham, R. B., McCrthy, M. A. 1999. Landscape analysis of the occurrence of arboreal marsupials in the montane ash forest of the Central Highlands of Victoria, southern Australia. Biological Conservation 89: 83-92.

Lindermayer, D. B., Margules, C. R., Botkin, D. B. 2000. Indicators of biodiversity for ecologically sustainable forest management. Conservation Biology 14: 941-950.

Linke, S., Norris, R. H., Faith, D. P., Stockwell, D. 2005. ANNA: A new prediction method for bioassessment programs. Freshwater Biology 50: 147-158.

Magalhães, M. F., Beja, P., Schlosser, I. J., Collares-Pereira, M. J. 2007. Effects of multi-year droughts on fish assemblages of seasonally drying Mediterranean streams. Freshwater Biology 52: 1494-1510.

Malmqvist, B., Rundle, S. R. 2002. Threats to the running water ecosystems of the world. Environmental Conservation 29: 134-153. 
Matthews, W. J. and Marsh-Matthews, E. 2003. Effects of droughts on fish across axes of space, time and ecological complexity. Freshwater Biology 48: 1232-1253.

Meffe, G. C., Minckley, W. L. 1987. Persistence and stability of fish and macroinvertebrate assemblages in a repeatedly disturbed Sonora desert stream. American Midland Naturalist 117: $177-191$.

Melcher, A., Schmutz, S., Haidvogl, G., Moder, K. 2007. Spatially based methods to assess the ecological status of European fish assemblage types. Fisheries Management and Ecology 14: 453-463.

Miller, D. L., Leonard, P. M., Hughes, R. M., Karr, J. R., Moyle, P. B., Schrader, L. H., Thompson, B. A., Daniel, R. A., Fausch, K. D., Fitzhugh, G. A., Gammon, J. R., Halliwell, D. B., Angermeier, P. L., Orth, D. J. 1988. Regional applications of an index of biotic integrity for use in water resource management. Fisheries 13: 12-20.

Moyle, P. B. and Marchetti, M. P. 1999. Application of indices of biotic integrity to California streams and watersheds. In: Simon, T. P. (ed.) Assessing the Sustainability and Biological Integrity of Water Resources Using Fish Communities. pp 367-380. Boca Raton, FL: CRC Press,.

Moyle, P. B., Randall, P. J. 1998. Evaluating the biotic integrity of watersheds in the Sierra Nevada, California. Conservation Biology 6: 1318-1326.

Munné, A., Prat, N., Solá, C., Bonada, N., Rieradevall, M. 2003. A simple field method for assesing the ecological quality of riparian habitat in rivers and streams: QBR index. Aquatic Conservation: Marine and Freshwater Ecosystems 13: 147-163.

Norris, R. H., Hawkins, C. P. 2000. Monitoring river health. Hydrobiologia 435: 5-17.

Oberdorff, T., Pont, D., Hugueny, B., Porcher, J. P. 2002. Development and validation of a fishbased index for the assessment of "river health" in France. Freshwater Biology 47: 17201734.

Pont, D., Hugueny, B., Rogers, C. 2007. Development of a fish-based index for the assessment of river health in Europe: the European Fish Index. Fisheries Management and Ecology 14: 427-439.

Prenda, J., Clavero, M., Blanco-Garrido, F., Menor, A., Hermoso, V., 2006. Threats to the c onservation to biotic integrity in Iberian fluvial ecosystems. Linmetica 25: 377-388.

Reynolds, L., Herlihy, A. T., Kaufmann, P. R., Gregory, S. V., Huges, R. M. 2003. Electrofishing effort requirements for assessing species richness and biotic integrity $\mathrm{n}$ western Oregon streams. North American Journal of Fisheries Management 23: 450-461.

Reynoldson, T. B., Norris, R. H., Resh, V. H., Day, K. E., Rosenberg, D. M. 1997. The reference condition: a comparison of multimetric and multivariate approaches to assess water-quality impairment using benthic macroinvertebrates. Journal of the North American Benthological Society 16: 833-852.

Roset, N., Grenouillet, G., Goffaux, D, Pont, D., Kestemont, D. 2007. A review of existing fish assemblage indicators and methodologies. Fisheries Management and Ecology 14: 393-405.

Sandin, L., Hering, D. 2004. Comparing macroinvertebrate indices to detect organic pollution across Europe: a contribution to the EC Water Framework Directive intercalibration. Hydrobiologia 516: 55-68.

Schmutz, S, Cowx, I. G., Haidvolg, G., Pont, D. 2007a. Fish-based methods for assessing European running waters: a synthesis. Fisheries Management and Ecology 14: 369-380.

Schmutz, S., Melcher, A., Frangez, C., Haidvolg, G., Beier, U., Böhmer, J., Breine, J., Simoens, I., Caiola, N., De Sostoa, A., Ferreira, M. T., Oliveira, J., Grenouillet, G., Goffaux, De Leeuw, J. J., Noble, R. A. A., Roset, N., Virbickas, T. 2007. Spatially based methods to assess the ecological status of riverine fish assemblages in European ecoregions. Fisheries Management and Ecology 14: 441-452.

Shields, F. D., Jr, Knight, S. S., Cooper, C. M. 1995. Use of the index of biotic integrity to assess the physical habitat degradation in warmwater streams. Hydrobiologia 312: 191-208. 
Simpson, J.C., Norris, R.H. 2000. Biological assessment of river quality: development of AUSRIVAS models and outputs. In Assessing the biological quality of fresh waters; RIVPACS and other techniques (eds J.F. Wright, D.W. Sutcliffe \& M.T. Furse), pp. 125-42. Freshwater Biological Association, Ambleside, Cumbria, U.K.

Thiollay, J. 1992. The influence of selective logging on bird species diversity in a Guianan rain forest. Conservation Biology 6: 47-63.

Van Sickle, J., Hawkins, C. P., Larsen, D. P., Herlihy, A.T. 2005. A null model for the expected macroinvertebrate assemblage in streams. Journal of the North American Benthological Society 24: 178-191.

Vanote, R. L., Minshall, G. W., Cummins, K. W., Sedell, J. R., Cushing C. E. 1980. The river continuum concept. Canadian Journal of Fisheries and Aquatic Science 37: 130-137.

Velasco, J., Rincon, P. A., Lobón-Cerviá, J. 1990. Age, growth and reproduction of the cyprinid Rutilus lemmingii (Steindachner, 1866) in the river Huebra, central Spain. Journal of Fish Biology 36: 469-480.

Vila-Gispert, A., Moreno-Amich, R. 2002. Life-history patterns of 25 species from European freshwater fish communities. Environmental Biology of Fishes 65: 387-400. 
Table 1. Environmental variables used to characterize the sampled sites. * Denotes humanbiotic potentially perturbed variables and used to describe stressor gradients.

\begin{tabular}{|c|c|c|c|c|}
\hline Scale & Variable & Method & Mean & Range \\
\hline \multirow[t]{26}{*}{ Site } & Water depth $(\mathrm{cm})$ & In situ & 42.8 & $7.0-200$ \\
\hline & Shelter availability ( $\mathrm{m}^{2}$ of shelter/river width) & In situ & 5.6 & $0.0-60.6$ \\
\hline & Elevation $(\mathrm{m})$ & GIS & 384.1 & $7.1-974.9$ \\
\hline & $\begin{array}{l}\text { Relative position (dist. to the most headwater } \\
\text { point/total length of the stream) }\end{array}$ & GIS & 0.47 & $0.04-1.00$ \\
\hline & Stream order (Strahler) & GIS & 2.1 & $1.0-6.0$ \\
\hline & Distance to headwater $(\mathrm{Km})$ & GIS & 68.1 & $3.6-1,036.1$ \\
\hline & Distance to Guadiana River (Km) & GIS & 58.2 & $0.0-196.0$ \\
\hline & River width $(\mathrm{m}) *$ & In situ & 10.8 & 1.4-123.0-1.4 \\
\hline & Substrate coarseness (Wentworth scale) * & In situ & 5.3 & $1.0-9.0-1.0$ \\
\hline & Riparian Quality Index (QBR, Mune et al. 2003)* & In situ & 61.8 & $0-100$ \\
\hline & $\mathrm{NH}_{4}^{+}(\mathrm{mg} / \mathrm{L}) *$ & In situ & 1.38 & $0.02-51.60$ \\
\hline & $\mathrm{NO}_{2}^{-}(\mathrm{mg} / \mathrm{L}) *$ & In situ & 0.10 & $0.01-2.00$ \\
\hline & $\mathrm{NO}_{3}^{-}(\mathrm{mg} / \mathrm{L}) *$ & In situ & 4.09 & $0.50-55.90$ \\
\hline & $\mathrm{PO}_{5}^{3-}(\mathrm{mg} / \mathrm{L}) *$ & In situ & 1.00 & $0.05-23.20$ \\
\hline & $\mathrm{SO}_{4}^{2-}(\mathrm{mg} / \mathrm{L}) *$ & In situ & 110.1 & $10.0-2380.0$ \\
\hline & $\mathrm{Cl}^{-}(\mathrm{mg} / \mathrm{L}) *$ & In situ & 56.1 & $2.0-834.0$ \\
\hline & Water temperature $\left({ }^{\circ} \mathrm{C}\right) *$ & In situ & 20.5 & $9.4-32.6$ \\
\hline & Conductivity $(\mu \mathrm{S} / \mathrm{cm}) *$ & In situ & 624.7 & $38.0-3230.0$ \\
\hline & $\mathrm{pH} *$ & In situ & 7.84 & $2.21-10.63$ \\
\hline & Annual precipitation $\left(\mathrm{mm} / \mathrm{m}^{2}\right)$ & GIS & 593.1 & $370.2-1114.5$ \\
\hline & Solar radiation $\left(10 \mathrm{KJ} / \mathrm{m}^{2} *\right.$ dia $\left.* \mu \mathrm{m}\right)$ & GIS & 2033.9 & $1646-2227$ \\
\hline & Average annual air temperature $\left({ }^{\circ} \mathrm{C}\right)$ & GIS & 15.85 & $13.0-18.0$ \\
\hline & Distance to the nearest reservoir upstream $(\mathrm{Km}) *$ & GIS & 41.1 & $0.0-196.0$ \\
\hline & Distance to the nearest reservoir downstream $(\mathrm{Km}) *$ & GIS & 25.9 & $0.2-115.8$ \\
\hline & $\%$ Exotic abundance & In situ & 39.6 & $0-100$ \\
\hline & $\%$ Exotic species richness & In situ & 36.1 & $0-100$ \\
\hline \multirow[t]{7}{*}{$\operatorname{Reach}(500 \mathrm{~m})$} & Slope $(\%)$ & GIS & 5.92 & $0.00-58.03$ \\
\hline & Sinuosity & GIS & 1.23 & $1.00-2.79$ \\
\hline & Land uses & & 1.0 & $0.0-36.0$ \\
\hline & Urban/Industrial $(\%) *$ & GIS & & \\
\hline & Intensive agriculture $(\%) *$ & GIS & 29.0 & $0.0-100.0$ \\
\hline & Extensive agriculture $(\%) *$ & GIS & 7.0 & $0.0-100.0$ \\
\hline & Natural $(\%) *$ & GIS & 63.0 & $0.0-100.0$ \\
\hline \multirow[t]{9}{*}{ Basin } & Basin area (Drainage surface in each site, $10^{3} \mathrm{Km}^{2}$ ) & GIS & 260.1 & $0.9-5919.1$ \\
\hline & Gravelius index & GIS & 1.68 & $1.14-2.68$ \\
\hline & Land uses & & 0.4 & $0.0-6.7$ \\
\hline & Urban/Industrial $(\%)^{*}$ & GIS & & \\
\hline & Intensive agriculture (\%)* & GIS & 22.5 & $0.0-97.0$ \\
\hline & Extensive agriculture $(\%)^{*}$ & GIS & 11.0 & $0.0-89.1-0.0$ \\
\hline & Natural $(\%)^{*}$ & GIS & 65.8 & $0.9-100.0$ \\
\hline & Reservoir $(\%)^{*}$ & GIS & 0.32 & $0.0-21.2$ \\
\hline & Population density $\left(\mathrm{Hab} / \mathrm{Km}^{2}\right)^{*}$ & GIS & 21.0 & $0.0-459.3$ \\
\hline
\end{tabular}


Table 2. Principal Component Analysis carried out in the whole habitat-biotic variables data set listed in Table 1 except QBR. Only variables with loadings $>0.6$ in any Principal Component (PC) are shown. \% of explained variance (in brackets) and eigenvalues are also shown.

Denomination denotes the name for each PC in the text.

\begin{tabular}{|c|c|c|c|}
\hline Variable & $\begin{array}{c}\text { PC1_Alt } \\
(13.0 \%) \\
5.4\end{array}$ & $\begin{array}{c}\text { PC2_Alt } \\
(13.0 \%) \\
5.4\end{array}$ & $\begin{array}{c}\text { PC3_Alt } \\
(11.0 \%) \\
4.5\end{array}$ \\
\hline Denomination & $\begin{array}{l}\text { Longitudinal } \\
\text { gradient }\end{array}$ & $\begin{array}{c}\text { Habitat } \\
\text { impairment }\end{array}$ & $\begin{array}{c}\text { Biotic } \\
\text { perturbation }\end{array}$ \\
\hline Basin area & 0.9 & & \\
\hline Distance to headwayer & 0.9 & & \\
\hline River order & 0.9 & & \\
\hline River width & 0.8 & & \\
\hline Gravelius Index & 0.6 & & \\
\hline Water depth & 0.6 & & \\
\hline Reach Int. Agr. & & -0.9 & \\
\hline Basin Int. Agr. & & -0.9 & \\
\hline $\mathrm{SO}_{4}^{2-}$ & & -0.9 & \\
\hline $\mathrm{NO}_{3}^{-}$ & & -0.8 & \\
\hline Substrate coarseness & & -0.6 & \\
\hline Basin Natural land & & 0.6 & \\
\hline Precipitation & & 0.9 & \\
\hline Reach Natural land & & 0.9 & \\
\hline \% Exotic Richness & & & -0.9 \\
\hline \% Exotic Abundance & & & -1.0 \\
\hline
\end{tabular}


Table 3. Effect of natural and perturbation gradients summed up in Table 2 on the Index of Community Integrity. Sum of squares (SS), F and associated $\mathrm{p}$ values are given for all the independent variables used in the General Lineal Model (GLM). The model displayed a global $\mathrm{R}_{\text {multiple }}^{2}=0.35, \mathrm{p}<0.001$. Significant effects are characterized by $\mathrm{p}<0.05$.

\begin{tabular}{lllll}
\hline & $\mathrm{SS}$ & $\mathrm{d} . \mathrm{f}$. & $\mathrm{F}$ & $\mathrm{p}$ \\
\cline { 2 - 5 } Intercept & 1526.08 & 1 & 2228.03 & $<0.001$ \\
Longitudinal gradient & 0.04 & 1 & 0.06 & 0.81 \\
Habitat impairment & 3.23 & 1 & 4.71 & 0.03 \\
Biotic perturbation & 53.37 & 1 & 77.92 & $<0.001$ \\
Error & 108.22 & 158 & & \\
\hline
\end{tabular}


Table 4. Quality classes for the Community Health Index. The cut-off points were established to maximize the index response to habitat and biotic impairment and reduce the risk of Type I and II errors.

\begin{tabular}{|c|c|c|c|}
\hline Quality class & Cut-off point & Aim & Interval \\
\hline HIGH & Percentil 95 Perturbed sites & $\begin{array}{l}\text { Less than } 5 \% \text { of Perturbed sites are misclassified as in high } \\
\text { condition (Reduced Type II error) }\end{array}$ & (6.46-10] \\
\hline GOOD & & & $(5.51-6.46]$ \\
\hline MODERATE & Mean Reference sites & $\begin{array}{l}\text { Only sites with a score higher than the mean scores within } \\
\text { sites in Reference condition are classified as Good }\end{array}$ & $(4.36-5.51]$ \\
\hline POOR & Mean Perturbed sites & $\begin{array}{l}\text { Only sites with a score higher than an average perturbed } \\
\text { site are classified as Moderate }\end{array}$ & $(3-4.36]$ \\
\hline $\mathrm{BAD}$ & Percentil 1 Reference sites & $\begin{array}{l}\text { Less than } 1 \% \text { of Reference sites are misclassified as in bad } \\
\text { condition (Reduced Type I error) }\end{array}$ & {$[0-3]$} \\
\hline
\end{tabular}




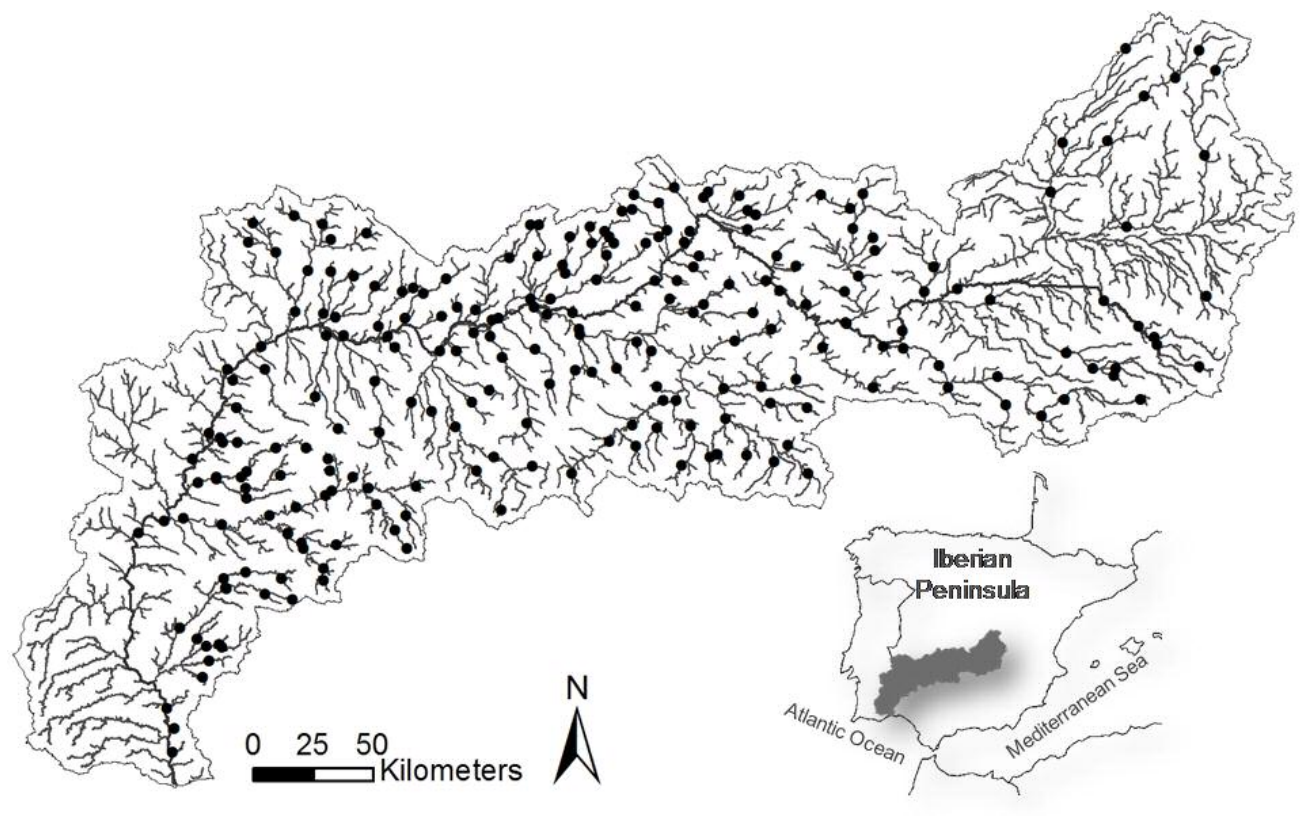

Figure 1. Guadiana River basin and location of sampling sites. $254 \times 165 \mathrm{~mm}(96 \times 96 \mathrm{DPI})$ 


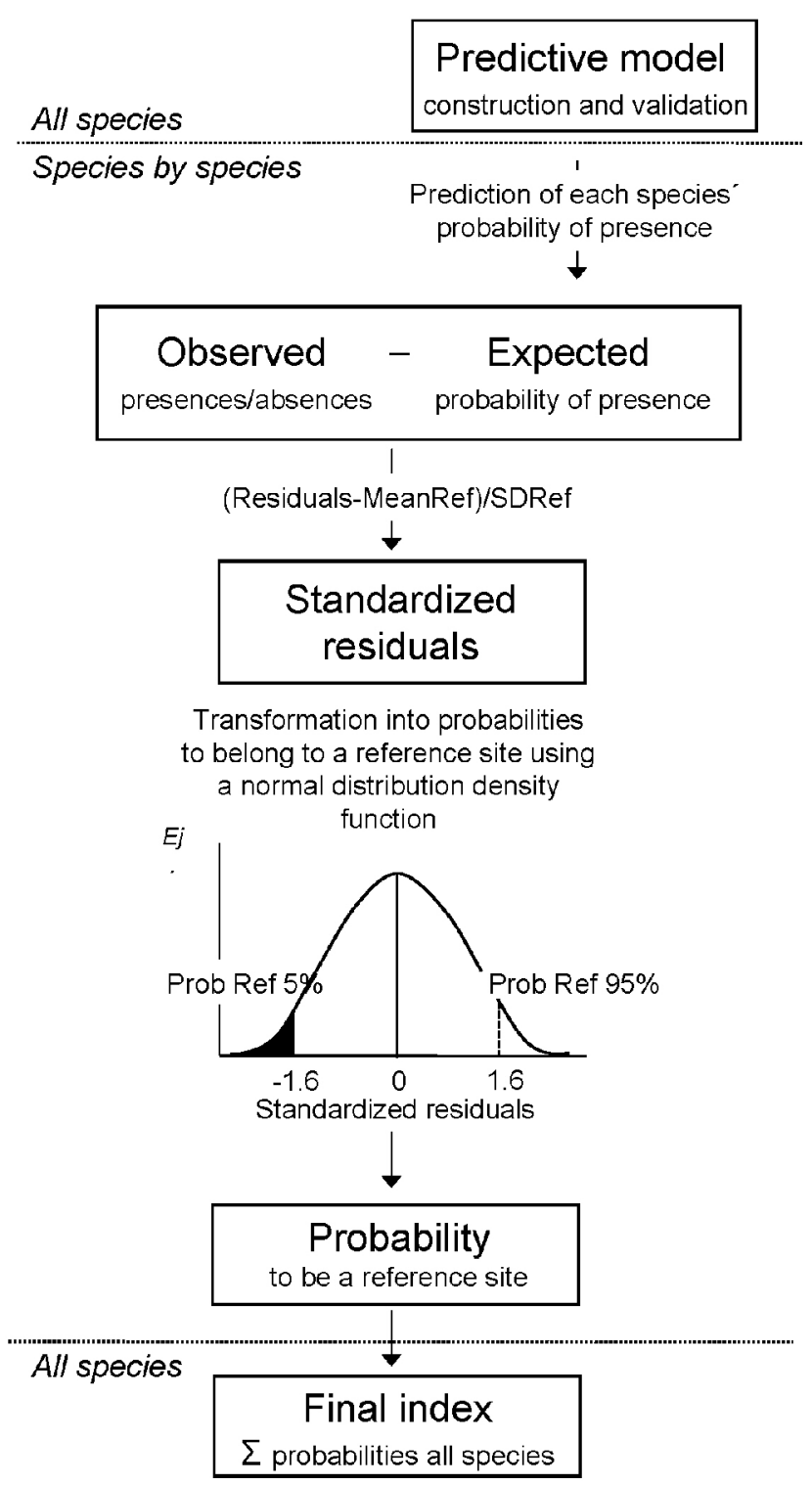

Figure 2. Flowchart for the development of Community Health Index. An example of the transformation of the standardized residuals into sites" probabilities to be a Reference site is showed. The accumulated probability for a low residual $(-1.6)$ is very low $(5 \%)$ while for a large one (1.6) is high (95\%). Dotted lines separate steps where the whole community (all species) or partial evaluations (species by species) are used. $147 \times 274 \mathrm{~mm}(200 \times 200 \mathrm{DPI})$ 


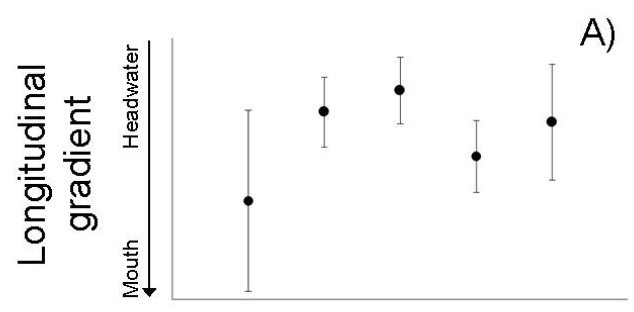

B)
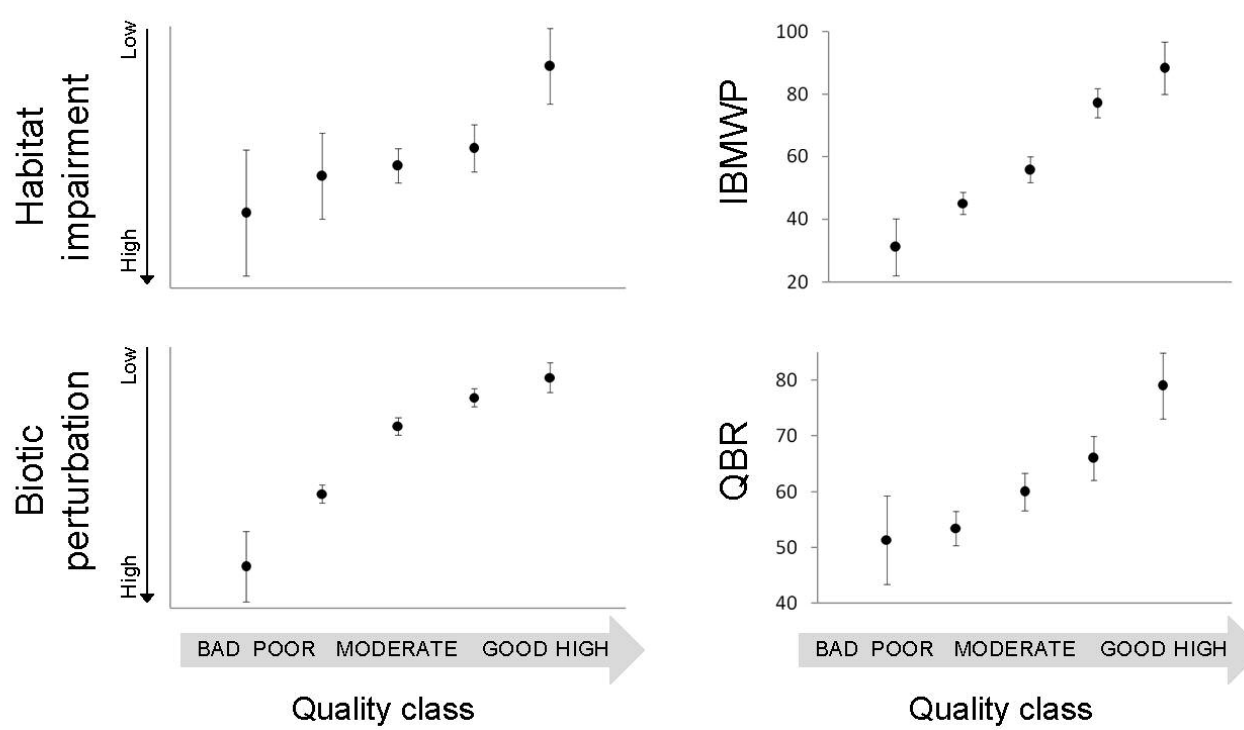

Figure 3. Index of Community Health scoring A) and validation B). For the scoring process the Principal Components detailed in Table 2 were used. The response of the index vs. other two common indices was used for validating it ability to give at least the same information. Mean \pm SE values are shown. $F$ and $p$ values from ANOVA analysis are also given.

$253 \times 210 \mathrm{~mm}(129 \times 129$ DPI $)$ 